Article

\title{
Analysis of Sustainable Development Questions of College Entrance Examination Geography Papers in China: 2010-2020
}

\author{
Fengtao Guo ${ }^{1}\left(\mathbb{D}\right.$, Yushan Duan ${ }^{1, *}$, Shanbo $\mathrm{He}^{2}$, Qian Gong ${ }^{3, *}$ and Zeyang Yao ${ }^{1}$ \\ 1 School of Geographic Sciences, East China Normal University, Shanghai 200241, China; \\ fengtao.guo@foxmail.com (F.G.); yaozeyang90@126.com (Z.Y.) \\ 2 Guangzhou No. 65 Middle School, Guangzhou 510450, China; heshanbo126@126.com \\ 3 School of Teacher Education, Nanjing Normal University, Nanjing 210023, China \\ * Correspondence: ysduan@geo.ecnu.edu.cn (Y.D.); clairegong@126.com (Q.G.); Tel.: +86-13701715221 (Y.D.)
}

check for

updates

Citation: Guo, F.; Duan, Y.; He, S.;

Gong, Q.; Yao, Z. Analysis of

Sustainable Development Questions

of College Entrance Examination

Geography Papers in China:

2010-2020. Sustainability 2022, 14 ,

1526. https://doi.org/10.3390/

su14031526

Academic Editor: María Luisa de

Lázaro y Torres

Received: 29 November 2021

Accepted: 24 January 2022

Published: 28 January 2022

Publisher's Note: MDPI stays neutral with regard to jurisdictional claims in published maps and institutional affiliations.

Copyright: (c) 2022 by the authors. Licensee MDPI, Basel, Switzerland. This article is an open access article distributed under the terms and conditions of the Creative Commons Attribution (CC BY) license (https:// creativecommons.org/licenses/by/ $4.0 /)$.

\begin{abstract}
International consensus has been reached for the 2030 Agenda, and governments have adopted measures for the gradual implementation of Sustainable Development Goals (SDGs). In this implementation, education plays a crucial role. Recently, the extent to which Education for Sustainable Development (ESD) has become the norm in national curricula, teacher education, and student assessment has been a focus of extensive research. The present study introduces the geography curriculum and the reform of the National College Entrance Examination (NCEE) in China in the 2000s. A global indicator framework for SDGs is used to analyze sustainable development (SD) content and characteristics in NCEE geography papers. Findings reveal that SD accounts for an average of $71 \%$ of score points among the 24 sets of papers. Sustainable agriculture, terrestrial ecosystems, settlements, and water are well reflected in questions, especially water-related ecosystems, resilient agricultural practices, transportation system, tourism, desertification, and degraded land and soil. Sustainable development questions have the characteristics of setting open questions, paying attention to question situation, being close to real life, being moderately difficult, paying attention to regional SD and human-nature relationship, and diversifying question-setting patterns. According to the analysis of papers, SD plays an important role in geography education.
\end{abstract}

Keywords: college entrance examination; geography; exam questions; sustainable development; characteristic; assessment

\section{Introduction}

In the 2015 UN General Assembly, 193 member nations adopted the 2030 Agenda for Sustainable Development to attain strong sustainability in the pursuit of 17 Sustainable Development Goals (SDGs) [1]. A global framework with 231 unique indicators was developed and refined to track the progress of the SDGs and targets [2,3]. Indicators regarding education were placed under targets 4,12 , and 13. That is the extent to which (i) global citizenship education and (ii) education for sustainable development are mainstreamed in (a) national education policies; (b) curricula; (c) teacher education; and (d) student assessment. One of the key points was the extent to which education for SD has become part of student assessment [2].

Numerous studies have examined student assessment of Education for Sustainable Development (ESD), while very few are developed for geography tests. Geography has a tradition of investigating human-environment interactions and nearly all action themes of ESD have a geographical dimension [4] $(42,27-38)$. In China, geography education is high-stakes, especially in the National College Entrance Examination (NCEE), commonly known as Gaokao. Students who choose the social science concentration in NCEE requires testing in Geography [5].

In this study, the primary goal is to analyze the situation, achievement, and the normalization of SD in high school geography for China. 
This study is guided by three questions, as follows:

(1) How does ESD reflect high geography curriculum in China?

(2) How does ESD reflect high geography assessment in China?

(3) What are the characteristics of geography in NCEE tests for SD?

At last, the type of questions foster ESD will be discussed in sense of powerful knowledge.

\section{Literature Review}

Education plays a crucial role in the implementation of the SDGs [6,7]. On the basis of embedding sustainability values, ESD has been incorporated in the school curricula (e.g., in science subjects, geography, and social studies) $[8,9]$.

Among all the subjects in basic education, geography is one of the most suitable for ESD [10]. Geography offers a uniquely powerful means of seeing and understanding the world, making connections between scales such as from global to local [11], and identifying opportunities and challenges [12]. This subject is uniquely positioned to link different disciplines together, especially social and environmental elements. As such, geography has become important for answering SD process questions and causal relationships [12].

The ESD studies can be grouped in two categories. One focuses on educator competence to teach and practice sustainability [13-15] while the other designs instruments for assessment to measure SD knowledge, attitude, behavior [16], skills, and values in sustainability [5,17]. In the latter category, rubrics are created and used to assess pupils performance [18].

Apart from the paucity of work that focuses on school education, most of the existing studies only examine a certain region or school, without concluding current assessment situations of ESD from a larger spatial perspective.

Literature has extensively studied the geography questions in China's NCEE, but less research has been done from the SD perspective. Furthermore, most studies examine geography exam questions in a certain year [19] or for five years [20], thereby lacking research and analysis for a round of curriculum reform.

Nearly all studies for the geography exam questions are carried out by teachers to improve students' results and instruction. Therefore, research focuses mainly on test points including geography knowledge, skills, and problem-solving techniques [21]. Three NCEE geography questions are set to explore the thinking mode of answering questions regarding the SD of agricultural products [22]. The exam questions are also classified and analyzed [20]. In addition, several geography teachers consider the design of exam questions for regional SD $[23,24]$ but do not analyze their degree of normalization and characteristics of exam questions.

Therefore, this study examines the content and characteristics of SD in NCEE geography questions for over 10 years.

\subsection{High School Geography Curriculum}

In 2003, the Ministry of Education (MOE) of the People's Republic of China (PRC) promulgated the curriculum standards (new curriculum standard) for 15 subjects, including geography [25], which ushered in the eighth curriculum reform of ordinary high schools in China. Since the autumn of 2004, all Chinese provinces have begun adopting the new curriculum.

In high school, geography consists of three compulsory modules and seven optional ones (Figure 1) [26]. The theory of SD is the core topic of teaching content [27,28]. Students are required to sort out and analyze geographical phenomena in life, gradually learn to use basic relevant principles to explore geographical processes, causes, and laws of geography [29]. 


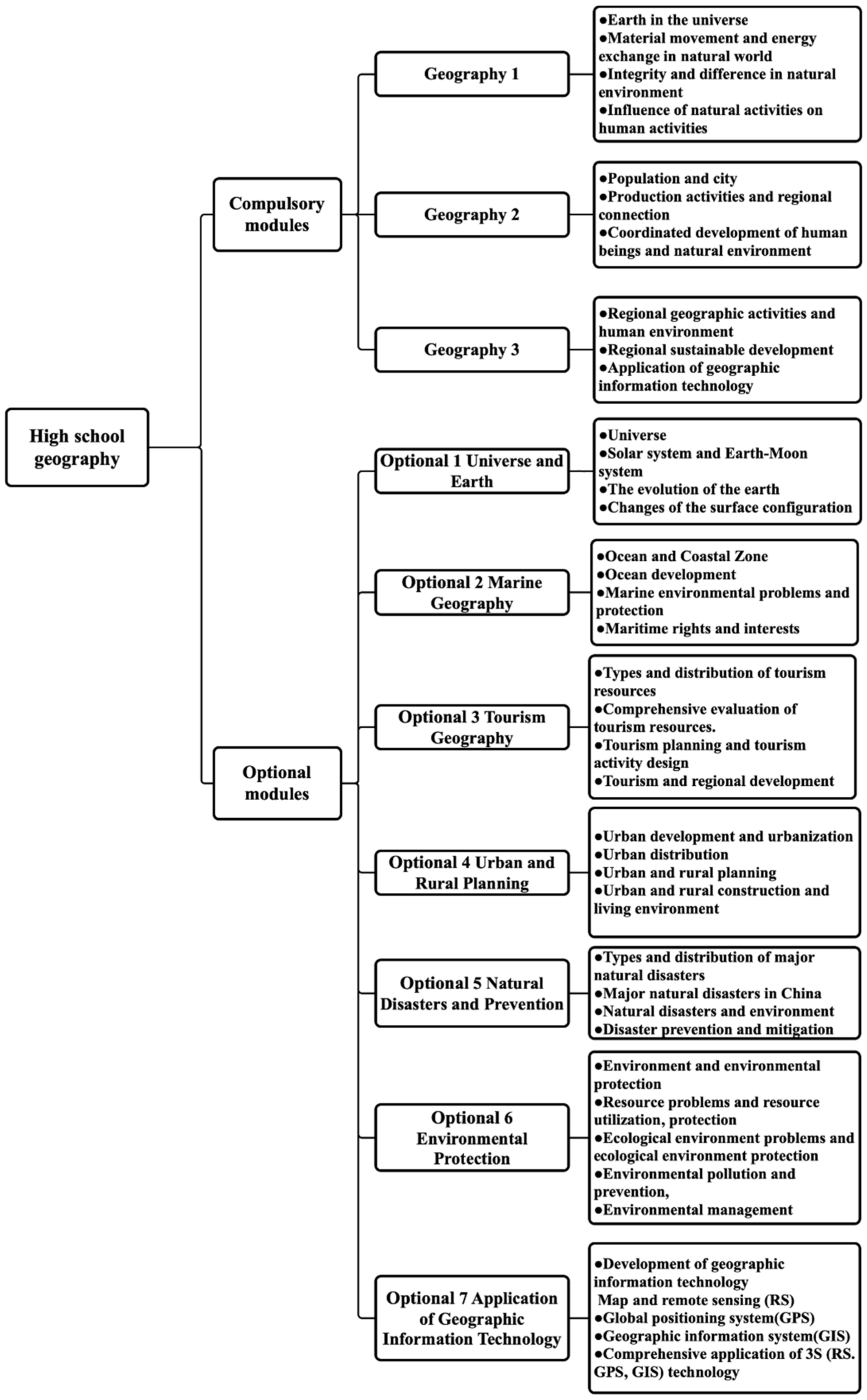

Figure 1. High-school geography curriculum content structure. 


\subsection{NCEE}

NCEE is closely related to administrative divisions. Students are restricted by the "hukou" system in NCEE, with the enrollment mark that is not uniform and rather determined by province [30]. Recently, the new system has reversed exam-oriented education [31] and the situation of evaluating students based on scores alone [32]. The NCEE may not be the best but remains the most feasible system [33] as an important talent selection in China.

At present, the question-setting method of NCEE is a "dual-track system," that is, national unified and provincial methods [34]. The provincial question-setting program has been officially promoted since 2004 , and at most 16 provinces participate in independent question-setting [35]. In recent years, due to reasons of "cost is too high" and "unfavorable to the rational flow of talents" [32], only a few provinces and cities continue to implement independent question-setting.

The examination for the new curriculum standard started in 2007, and most of the geography exam questions are included in the social science concentration papers. Several provinces and cities such as Shanghai set geography questions in a separate paper. The national unified paper of the new curriculum standard was not released by the National Education Examinations Authority (NEEA) until 2010 [36].

With more provinces joining the examination for the new curriculum standard, China now has three national unified test papers, I-III, to meet the varying regional needs. Take 2020 as an example (Figure 2). Paper I is mainly applied to the central and Southeast China with a large population and developed economy. Paper II is used in the Northeast and Northwest China while Paper III is used in the Southwest provinces.

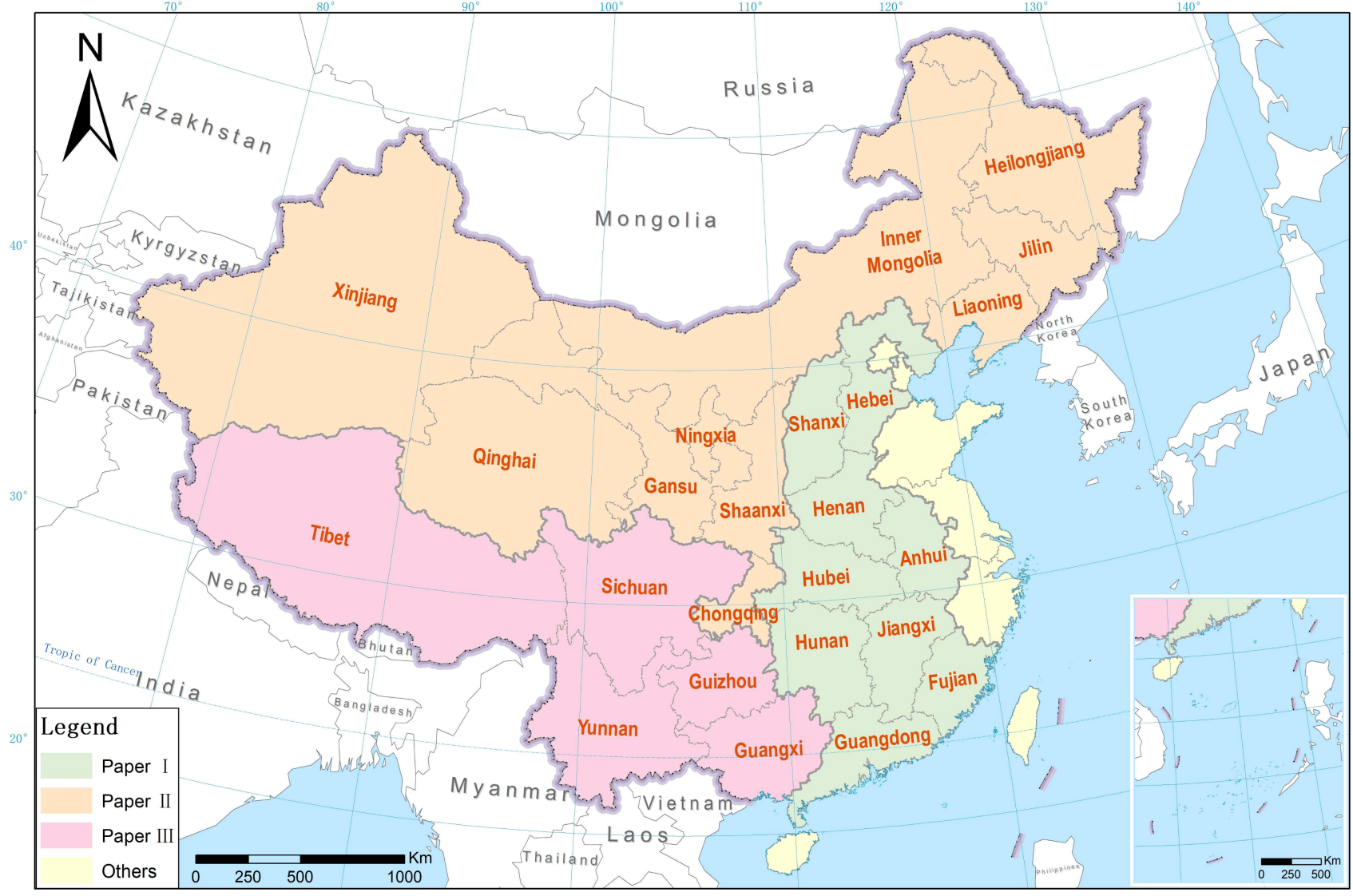

Figure 2. Usage distribution map of national unified papers in 2020. 


\section{Materials and Methods}

This study selects the national unified social science concentration papers for the new curriculum standard released by NEEA from 2010 to 2020. The reason is the increased quality of geography exam questions and greater influence than provincial question-setting.

All required and optional questions of 24 geography papers are analyzed, with a total of 372 questions from 2010 to 2020. The structure, question types, and quantity of the geography tests in the national unified papers are stable and include required and optional questions. The required questions include 11 multiple-choice types with a total of 44 points, and two essay questions with 3-4 short items with a total of 46 points. The optional questions correspond to the optional modules of geography curriculum with 10 points for each question. One of 2-3 essay questions must be selected and answered.

This study adopts qualitative and quantitative methods according to the global framework by the Inter-Agency and Expert Group on SDG Indicators [2]. The steps taken are as follows.

\section{(1) Expert consultation}

Through WeChat, seven experts are invited and asked, "Which targets are related to geographical education in terms of the global indicator framework?" The targets that are irrelevant to geography teaching are removed to obtain an analytical framework, which covers 17 goals and 71 targets (see Appendix A Table A1). Finally, the targets of SD are selected and confirmed in accordance with expert consultation and discussion of authors.

\section{(2) Content analysis}

The related SD is analyzed and listed in terms of geography standard [26] and document literature [29]. Subsequently, a college instructor and a geography teacher in middle school analyze the geography questions according to the analysis framework. The questions related to SD are categorized by their corresponding goal and targets. SD questions are classified into 48 targets, each of which corresponds to the most relevant target. The percentage of questions the judges agreed on was $87.5 \%$ which is acceptable for this study. About 30 questions were identified by a geography teacher but not a college instructor. Most of questions direct to zero hunger and sustainable cities and communities including targets 2.3, 2.4, 2.5 11.2, 11.a, 11.3, 11.5, 3.7, and 17.10. The other 4 questions are identified with an inconsistent category. They are No. 36 in Paper I of 2018, No. 36 in Paper I of 2017, No. 36 in Paper I of 2016, and No. 36 in Paper I of 2015 II. For those 4 questions, the discrepancy is that the question should be divided in Target 17.9 "capacity-building" or Target 17.6 "technology" of international cooperation. Those differences are discussed with other authors and reach an agreement.

The test point base, the exam syllabus [37], and characteristics of SD questions are also analyzed and summarized in order to see how SD was integrated into the geography assessment. The exam syllabus and the requirement curriculum standard are in line with each other, but the former places an emphasis on the specification of question-setting. The characteristics of SD questions were summarized by type, source, question-setting method (question stem and questions), content (nature of geography), and difficulty of exam question. The judgment agreed on of test points is $100 \%$ and that of characteristics is $99 \%$. Moreover, the characteristics are not suitable to all the exam questions but represent how SD questions are set in exams.

\section{(3) Statistical analysis}

In order to clearly assess the degree of normalization for SD in geography questions, the total score or percentages for each goal and target was calculated according to geography papers. To better reflect the situation of SD in the geography test, we compare the papers under the new curriculum with the old curriculum (2009) and explain targets using test points of geography. All statistical analysis was based on the categories of global framework [2] and geography papers 2010-2020. 


\section{Results}

\subsection{Analysis of SD in National Geography Curricula and Exam Questions}

\subsubsection{SD Aspects in the High-School Curriculum}

In high school geography, SD is the guiding ideology; human-nature relationship is the main line and population, resources, environment, and development issues are the key points of design. The geography curriculum standard for high school clearly puts forward $\mathrm{SD}$ and requirements in nature of the course, curriculum rationale, design ideas, course objectives, content standard, and teaching suggestions (Table 1). "SD" appeared 19 times in the geography questions (Table 1), and its concept permeated the high school geography curriculum system.

The contents of the three compulsory modules are progressive. Although "Geography 1 " did not mention SD directly, it focuses on natural geography (Figure 1), including the traditional contents such as the universal environment, four spheres of the Earth, and the integrity and difference of the natural environment. The module does not stick to purely physical geographical structure. The contents of "the influence of the natural environment on human activities" is closely related to SD. "Geography 2" is human geography-oriented and includes population and cities, locational factors in industry and agriculture, and other classic content. The module ends with "Coordinated development of human beings and geographical environment," which expounds the origin, connotations, and tasks of SD. For example, "Understand the historical evolution of the thought of man-nature relationship. According to the relevant information, summarize the main environmental problems faced by human beings" (the others in Table 1). "Geography 3" is centered on SD, and introduces the relationship between the region and human beings as well as the development and regulation of the region [29].

In addition to the word "SD," much content that are closely related to SD are included in the optional modules (Figure 1), such as Marine Geography, Natural Disasters and Prevention, Environmental Protection, and Tourism Geography.

\subsubsection{SD Aspects in Geography Assessment}

Geography questions are closely related to the goals of SD. By statistics, exam questions with total scores of 90-120, 80-90, and 0-80 account for one third of the 24 sets for geography among the three papers, respectively.

In Paper II of 2018, SD accounted for the highest content (89\%). In Paper I of 2017, although the SD score was only 56 points, its content accounted for more than half of the total score $(51 \%)$.

Geography questions for the new curriculum standard highlight the importance of SD. Compared with $40 \%$ of the 2009 NCEE paper for non-new curriculum standards by NEEA, an average of $71 \%$ contents of the 24 sets of national papers for the new curriculum standard refer to SD (Figure 3).

SD in the three optional questions (Environmental Protection, Tourism Geography, and Natural Disaster and Prevention) account for $96 \%$, with a higher proportion than the required questions. For example, as hot topics, natural disasters and prevention tend to evaluate students' analytical ability of the characteristics, causes, and countermeasures of natural disasters.

4.1.3. Sustainable Agriculture, Terrestrial Ecosystems, Settlements, and Water Are Well-Reflected in Geography Questions

The examined questions cover the sustainable development goals unevenly. In Figure 4, the total score of questions corresponding to Goal 2 "End hunger, achieve food security and improved nutrition and promote sustainable agriculture" is the highest, with 334 points accounting for $16.6 \%$. Distribution and locational choice of agriculture in geography papers are closely related to Goal 2 of SD. Goal 2 is mainly reflected in five targets, such as food security, agricultural methods to improve productivity and disaster resistance, seed banks, and agricultural technology. Most questions are linked to target 2.3 "agricul- 
tural productivity" and 2.4 "sustainable food production systems and implement resilient agricultural practices".

Table 1. Location and expression of SD in the high school geography curriculum standard.

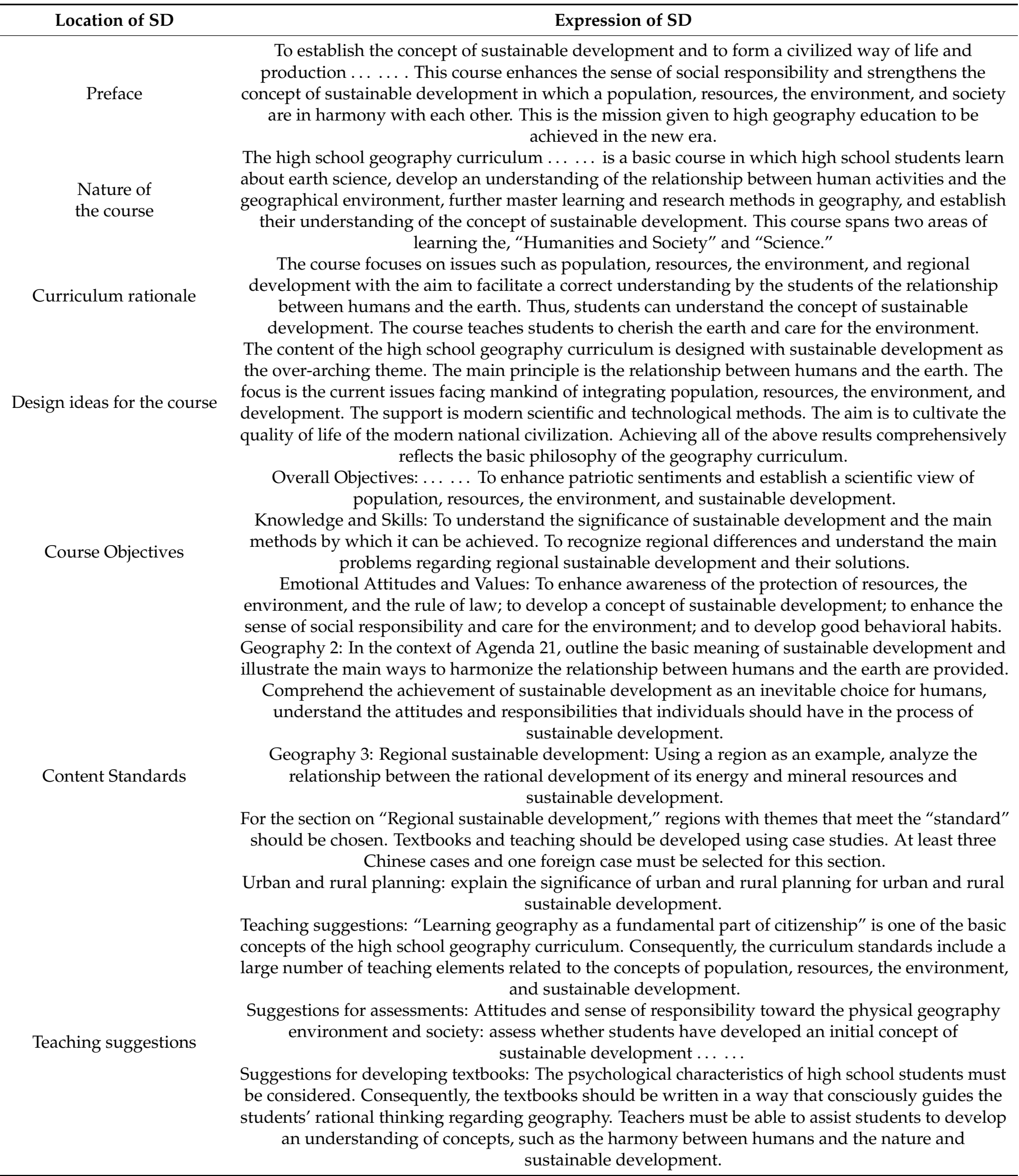

Note: this table was translated from geography curriculum standard. 


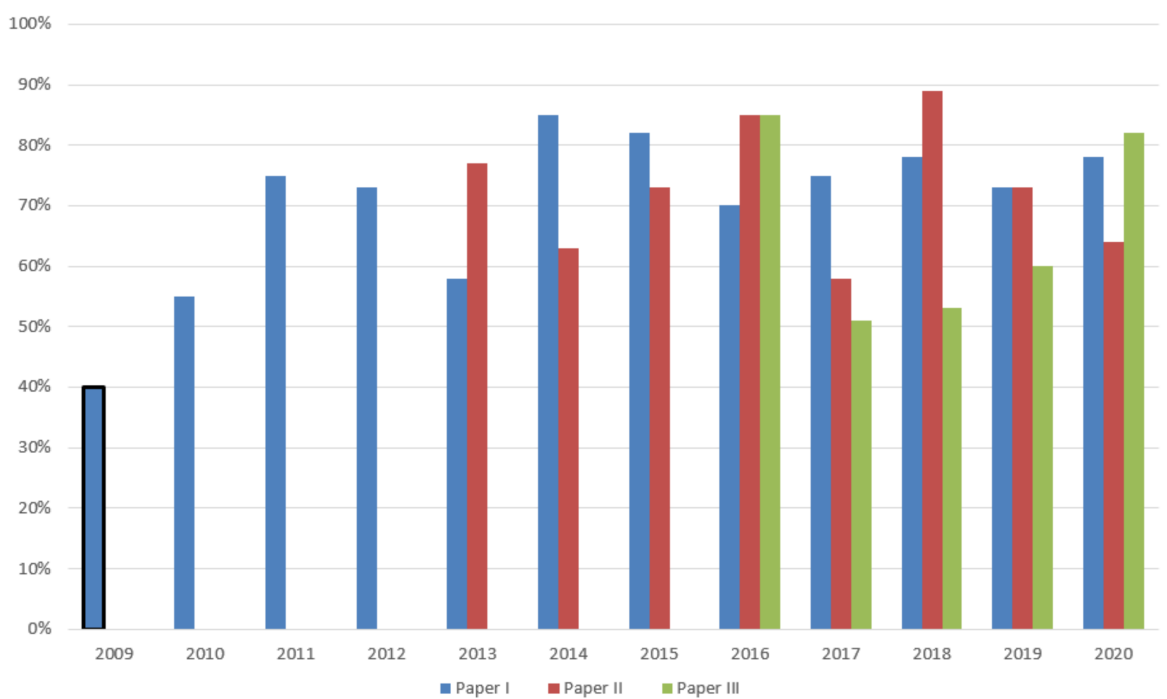

Figure 3. Percentage of scores for the questions on SD compared with the total scores for the paper.

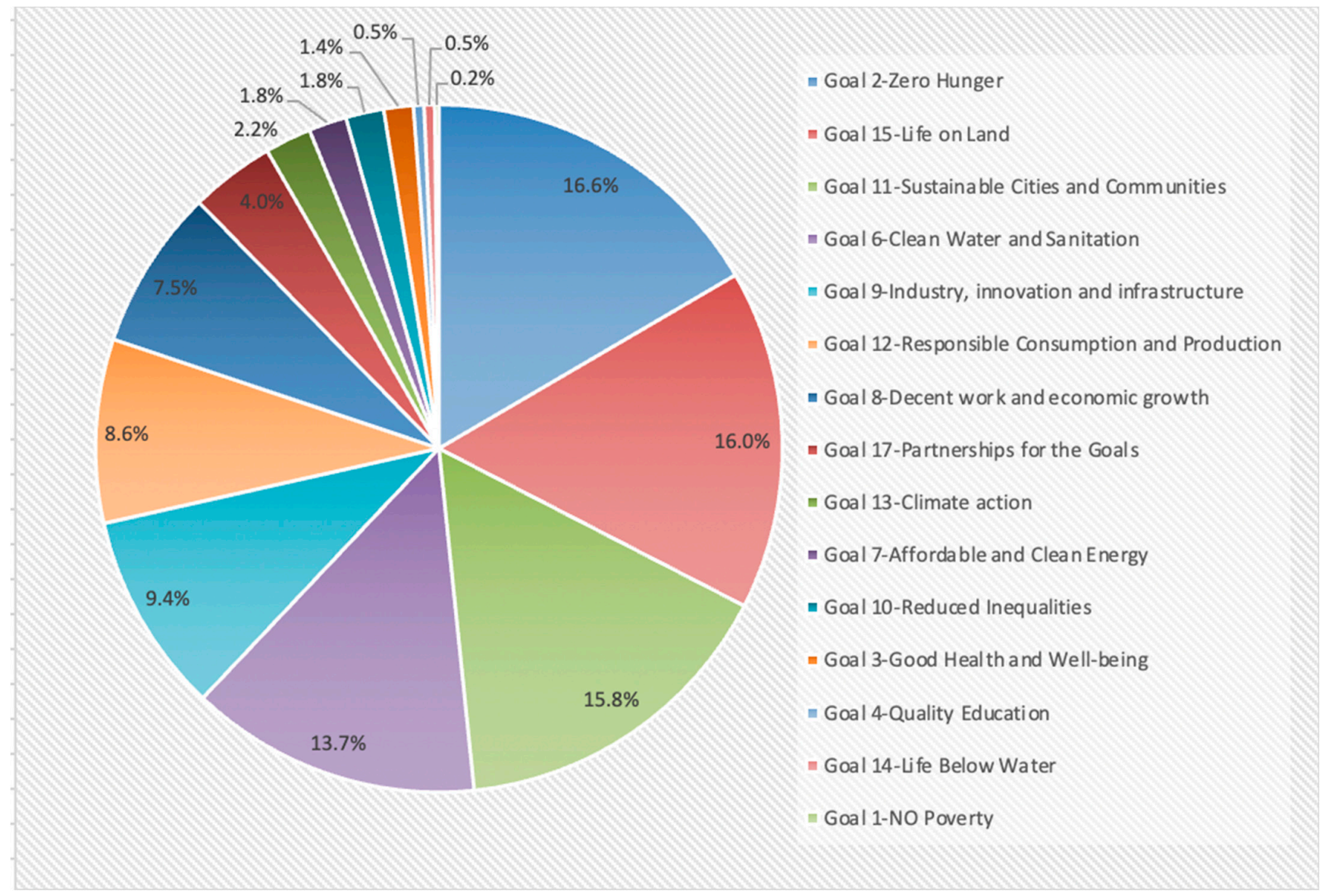

Figure 4. Proportion of the test scores for each goal in SD questions for all geography papers.

Goal 15 "protect, restore, and promote sustainable use of terrestrial ecosystems" represents $16 \%$ with seven targets, including prevention and control of land degradation, invasive alien species, biodiversity, sustainable management of forests, and conservation of freshwater and mountain ecosystems. Most questions pay much attention to investigate students' ability to control desertification and land degradation and less on invasive alien species and biodiversity, which are more inclined to biology than geography. 
Goal 11 for "sustainable cities and human settlements" with seven targets accounts for $15.8 \%$, including disaster resistance, sustainable buildings, cities, transportation systems, urban and rural development, adverse per capita environmental impact of cities, and social and environmental links between urban, peri-urban, and rural areas. The exam questions focus on the transportation system and only one is about the urban environment problem.

Goal 6 for "sustainable management of water" accounts for 13.7\% mainly reflected in four targets, such as improving water quality, implement integrated water resources management, protect and restore water-related ecosystems, wastewater treatment, and recycle and reuse technologies.

In addition, other goals are also reflected in the exam questions. For example, No. 36 (4) in Paper I of 2017 is "briefly describes the local benefits from China's investment in sisal farm in Tanzania," which embodies the international concept of win-win cooperation and common development that guides students to pay attention to local employment, taxation, infrastructure construction, and economic development situation.

However, Goals 5 "gender equality" and 16 "peace, justice and strong institutions" were not embodied in the geography questions. Climate change, energy, and ocean are also rarely included despite their close relation to geography.

4.1.4. Water-Related Ecosystems, Resilient Agricultural Practices, Transportation System, Tourism Desertification and Degraded Land and Soil Are Best Reflected

The analysis of the SD target gives a more detailed picture on what sustainable development goal the exam questions are focusing on. As shown in Figure 5 most questions are not related to zero hunger, as could be expected, but to clean water.

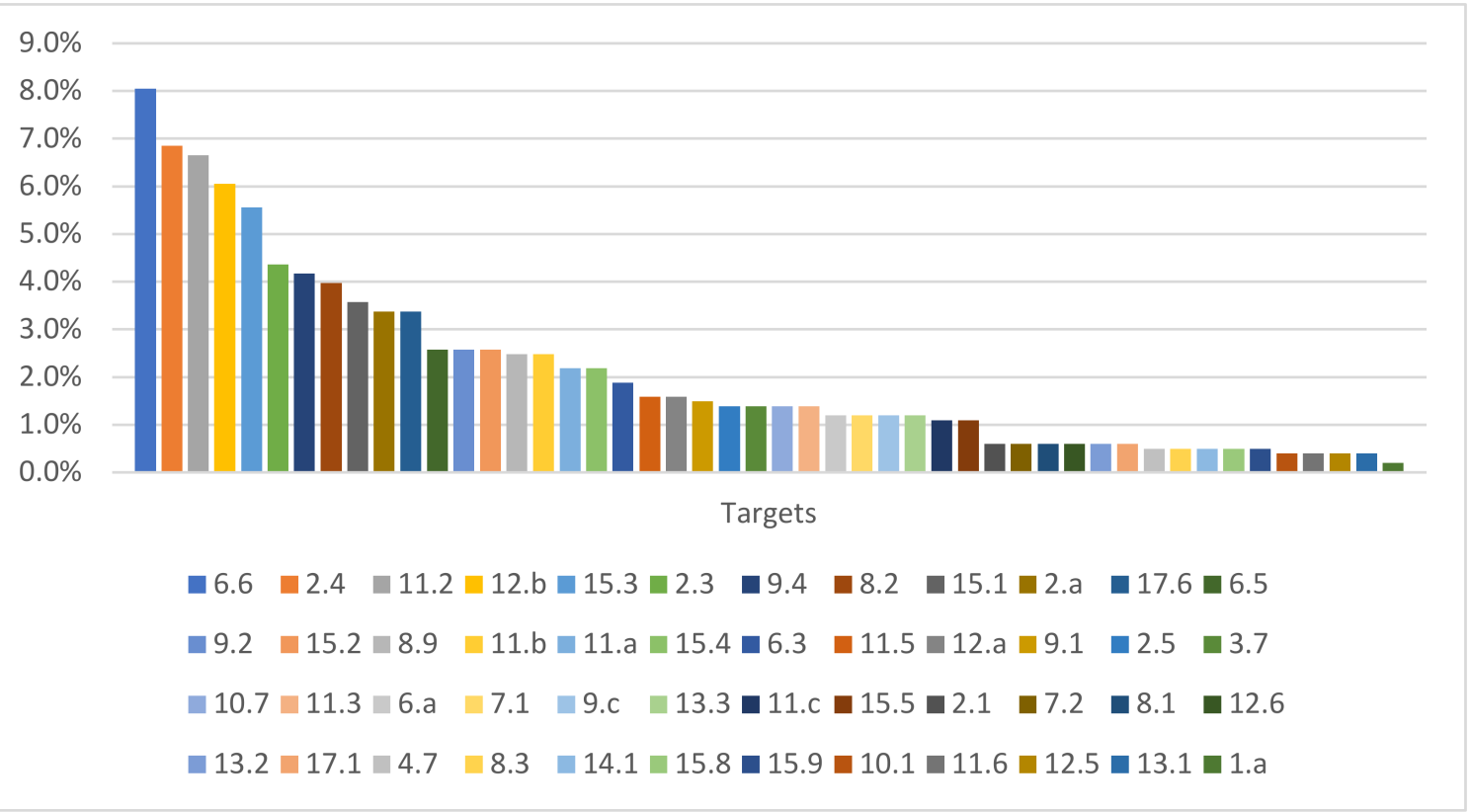

Figure 5. Percentage of SD targets in geography papers from 2010 to 2020.

Questions of SD which cover 48 targets point to the basic content and ability of geography. As shown in Figure 5, the targets are related to the natural system, fresh water, terrestrial ecosystem, disaster prevention and mitigation, locational factors of agriculture, industry and transportation, tourism and agricultural SD, and the influence of human activities on the natural environment.

First, the importance of water-related ecosystems (target 6.6) is most valued. Water is the source of life and the most important factor in the ecosystem. Rivers, wetlands, mountains, groundwater, and lakes are all important aspects of geography. According to the test syllabus, the questions of SD focus on the hydrological characteristics of rivers, 
measures and functions of ecological environment protection, problems caused by unreasonable use and the experience of rational utilization of resources, process and main links of water cycle, geographical significance of water cycle, and the countermeasures for comprehensive treatment of watershed. For example, two multiple-choice questions in Paper II of 2014 were designed for water cycle from the perspective of blue and green water in the ecosystem.

6. The largest proportion of green water is found in which of the following rivers:
A. Tarim River basin.
B. Yangtze River basin
C. Yarlung Tsangpo River basin
D. Heilongjiang River basin

7. In arid and semi-arid areas, which of the following measures would increase the proportion of productive green water the most:
A. conversion of paddy fields to dry fields
B. afforestation
C. mulching of crops
D. construction of terraces

Second, sustainable food production systems and resilient agricultural practices (target 2.4 ) is valued in the NCEE questions. Corresponding to the syllabus, the problems of regional agricultural production, methods and approaches of agricultural SD, regional factors of agriculture, and the influence of agricultural production activities on geographical environment are the common test points. For example, in No. 37 in Paper II of 2014, Jiansanjiang won the reputation of "China's Green Rice Capital," and students analyzed agricultural locational factors and SD methods from views of environmental quality, climatic conditions, and the planting process.

Third, sustainable transportation system (target 11.2) is also valued which mainly focuses on the influence of landform on transportation routes, influence of transportation modes and layout changes on settlements and commercial outlets, and the locational choice and rationality of transportation. For example, the landscape map of an uphill section of Qinghai-Tibet Railway was given in No. 11 in 2011 to investigate the function of engineering facilities. This question tests if students understand that the function of engineering facilities is to prevent the flood and sediment in the ditch from harming the railway and not to facilitate wildlife crossing the railway line and other choices.

Fourth, sustainable tourism (target 12.b) is presented clearly in questions, especially in the optional questions of Tourism Geography. Tourism has become an important leisure mode in China. Statistics reported 6.006 billion domestic tourists in 2019 [38]. Various places in China with unique natural resources and culture develop tourism industry for rural revitalization. In this section, the main test points include evaluating the conditions of the development of tourism resources, influence of the construction of tourist attractions on the geographical environment, and the role of tourism development on social economy and culture. For example, No. 43 of Paper II in 2020 is about how Hallstatt in Austria copied China to evaluate the effect of imitating famous foreign tourist attractions on local tourism development.

Finally, the combat of desertification and restoration of degraded land and soil (target 15.3) are well reflected in the geography questions. As an important natural element of geography, soil is closely related to environmental protection and the SD of agriculture and industry. The regional environment and development problems and measures and functions of ecological environment protection are the main contents of the exam. For example, No. 43 of Paper III in 2019 examines the students' ability to control soil secondary salinization of greenhouses in northern China. In 2015, the environment problem in karst landforms was evaluated in Papers I and II.

However, 23 targets related to geography were not represented in exam questions. For example, the resilience of the poor (target 1.5), built-up area of cities (target 11.7), equitable access to driking water (target 6.1), protection of marine and coastal ecosystems (target 14.2, $14.3,14.4,14 . a)$, under- 5 mortality rate (target 3.2), internatiaonal support for developing countries (target 8.a, 9.a, 10.a, 17.2 and 17.9), sustainable management of natural resources (traget 12.2), and food (target 12.3). 


\subsection{Analysis on the Characteristics of SD Exam Questions}

4.2.1. Set Open Questions for Evaluation of Students' SD Value

Beside the normal types of exam questions, open-ended questions are a bright spot. Open-ended questions without standard answers account for about $6.8 \%$. It often within Nos. 36 and 37 in the form of "whether it is feasible or not" or "whether you agree with the point of view or not," and explain the reasons. Compared with other questions, this type gives students more room to exert their personal abilities. Students can express their attitudes and understanding of geographical things according to their own values, which are conducive to exam students' concept of SD. For example, in No. 36 of Paper II in 2018, Botswana's soda plant often suffers from losses due to the adoption of new technology beneficial to environmental protection and the competition from American products. Thus, students can choose whether to support closing the soda plant or not and explain their reasons.

In addition, optional questions appear with the required questions of exam. This is a new way that differs from optional questions following the required questions. Students are asked to choose and answer one question. For example, in No. 36 of Paper I in 2016, students are asked to analyze the reasons of jasmine growth, planting, and industrial agglomeration in Hengxian County. Two questions are provided as follows:

(1) Explain the enlightenment of development experience of jasmine tea industry in Hengxian County to several impoverished counties in China.

(2) Put forward suggestions for further economic development of Hengxian County based on jasmine planting.

\subsubsection{Questions Are from Life and Influential Geographic Literature}

First, $33.2 \%$ of exam questions are from actual production and life, which correspond to the curriculum concept of "Learning Geography that is Useful for Life." The exam questions present actual situations to inspire students to explain the phenomena and develop the concept of SD through geographic knowledge and thinking. For example, No. 2 and 3 of Paper I in 2017 provide a photo of a city in eastern China (Figure 6). Students are asked to examine and analyze the reasons for landscape differences in the green belts and the factors restricting the planting of landscape plants. Several questions examine the students' ability to solve real-life problems. For example, No. 4, 5, and 6 in Paper I of 2020 examine how to use the prevailing wind in winter and summer to plan the architectural layout of the residential area in a city in the Northeast Plain (question 7).

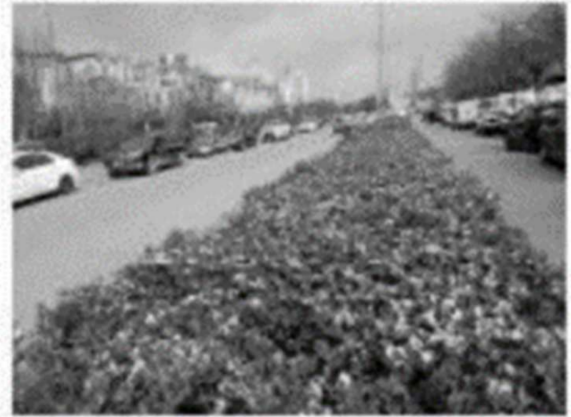

(a)

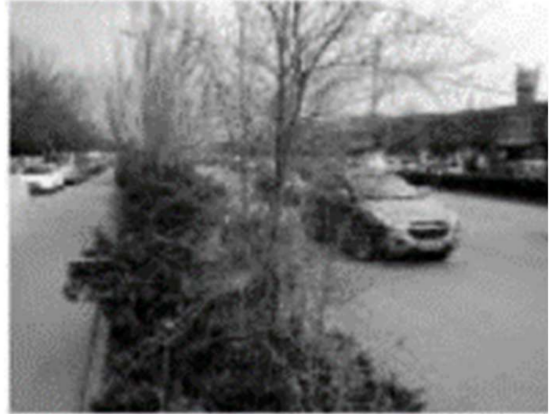

(b)

Figure 6. Landscape comparison of the green belts on both sides of a city in eastern China (taken on 25 March 2017) (a) motor vehicle lanes; (b) non-motor vehicle lanes.

Second, the question setting is scientific, mostly derived from influential geographic literature. This accounts for $6.8 \%$. For example, No. 36 in Paper II of 2016, driving from "French Rhone River and its Basin Harnessing" in the world regional studies [39]. The literature also relates to other disciplines. For example, No. 37 of Paper II in 2016 relates to 
the habitat change of giant pandas in China, sourced from a paper in the Chinese Journal of Zoology [40].

In China, the Qinling region in southern Shaanxi is a key area of the distribution range of the giant panda. The area was once an important forest logging area, with a number of forestry enterprises carrying out logging operations in the area from the 1970s, and logging of natural forests was completely stopped after 1998. Figure 5 illustrates the changes in the extent of suitable habitat for the giant panda in the area in 1976, 1987, and 2000 .

(1) Describe the changes in the extent of the giant panda's habitat in the area. (7 points)

(2) Analyze the anthropogenic causes of the changes in the extent of the giant panda's habitat in the area. (9 points)

(3) Describe the main ways in which road construction and the conservation of habitat for wildlife can be coordinated. (6 point)

Finally, $20.8 \%$ of the questions correspond to social hotspots. The SD questions guide students to care about national and international events to develop correct views on resources, the environment, and SD. Questions include topics such as industrial transfer, big data information, poverty alleviation, ecological civilization, clean energy, ecological agriculture, food security, e-commerce, and major traffic engineering. For example, No. 44 of Paper I in 2016 is concerned about environmental pollution problems that may be caused by abandoned express packaging and its possible solutions. No. 35 of Paper III in 2018 is about rural revitalization, how an aid impoverished peasant can become rich in the Dabie Mountains.

\subsubsection{Create Context of Problem in a Multiple Way}

In exam question, nearly all SD question have context with combination of text, map and picture, few questions consist of only text.

First, the map is an important venue of SD questions that is a unique language of geography. Questions with maps account for $35.2 \%$. Students can extract and analyze effective information and then use geographical knowledge and skills to solve problems using a map that has distinct characteristics. For example, Paper I of 2019 included six maps. Most maps in the exam questions are regional, including those with latitude and longitude, contours, and combinations of landscapes and schematic diagrams.

Second, the contexts are set in the question stems. This type of question accounts for $59.2 \%$. 'Text plus charts' is the main format of presenting the question stem. Typically, a situation is described with a piece of text and graphic material stating "where", "what", and other information. Each material is used in 2-3 multiple-choice questions, 3-4 comprehensive questions, and 1 optional question.

Finally, the question stems are concise in term of reading material. The words of multiple-choice questions have no more than 90 Chinese characters, and the words of comprehensive questions are usually about 120 Chinese characters.

\subsubsection{Diversifying Question-Setting Patterns with "Where, Why, and How"}

The SD exam questions in geography tend to focus on a question to examine whether students can analyze the reasons comprehensively and put forward corresponding strategies. The questions gradually deepen high order thinking of geography based on the $5 \mathrm{~W}$ method of geography [41], namely, what, where, why, when, and how. Exam questions can be created in several ways.

First, geographical attribution-measures. This model accounting for $66 \%$, generally based on materials, allows students to analyze local resources, environments, and development problems with geographical knowledge and skills, and then propose solutions. For example, No. 36 of Paper I in 2011 presents the map and the histogram of temperature and precipitation, enabling students to analyze the reasons and measures taken for the shortage of freshwater resources in Singapore and finally suggest their own measures. 
Second, geographical distribution and process-attribution analysis-measures. This type of questions accounts for 19.6\%. For example, No. 37 of Paper II of 2016 asked students to describe the changing state of the giant panda habitat, analyze the reasons for the change, and propose protective measures (see Figure 7).

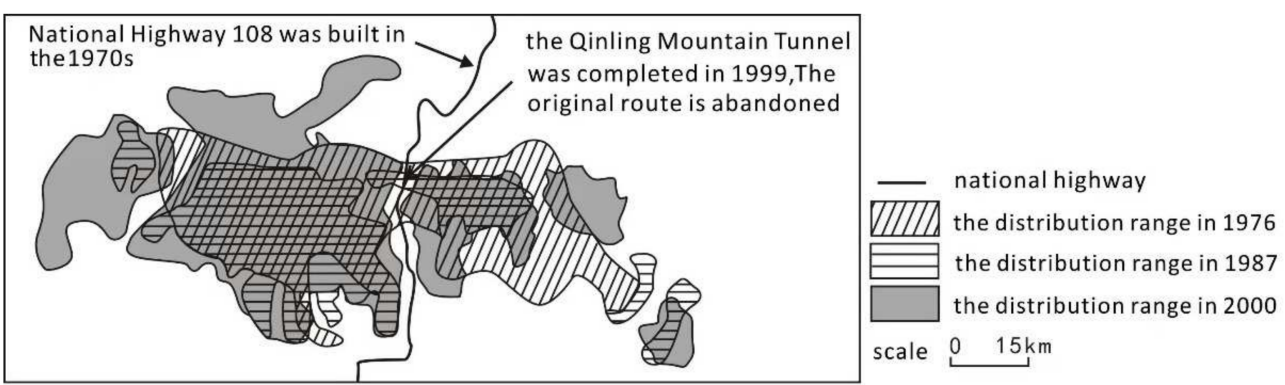

Figure 7. Changes of suitable habitat range for the giant panda in 1976, 1987, and 2000.

Third, analysis of advantages and disadvantages from geographical perspective. This type of questions accounts for $14 \%$. Students are asked to understand or solve the problems of SD through geographical factors. For example, No. 36 of Paper I in 2018 is based on China-Russian natural gas cooperation project and examines the advantages brought to the two countries. No. 44 of Paper III in 2018 analyzes the positive and negative effects of "Qianqiu Lake" fishing mode on migratory birds in Poyang Lake area.

\subsubsection{Focusing on Human and Nature Relationship}

The concept of harmony between man and land was also reflected in geography questions, mainly in two aspects.

First, the influence of human production activities on geographical environment and economic development are highlighted. These type of questions account for 27.2\%. For example, No. 37 of Paper I in 2013 discussed the influence of introducing Nile perch into Victoria Lake on local fish resources, fishing industry, and economic development. No. 7, 8, and 9 of Paper I in 2014 examine the influence of human activities on vegetation by increasing atmospheric nitrogen deposition. No. 1, 2, and 3 of Paper II in 2015 ask about the influence of industrialization and urbanization in the Pearl River Delta region on traditional pond agriculture.

Second, the effect of the natural environment on human activities are examined. This type of questions accounts for 25.2\%. For example, No. 9, 10, and 11 of Paper II in 2018 focus on the location, function, and characteristics of underground houses in Australian mining areas, respectively.

\subsubsection{Pay More Attention to Regional Sustainability}

First, SD issues are explored from the local, regional, and national, to an international scale. Areas with different scales, types, and functions are selected to help students understand the integrity and differences of regional geographical environment, and then analyze the relationship between environment and human activities. These type of questions account for $51.6 \%$. The questions include the topographic map of certain places (No. 1-3 of Paper \# 2010), schematic diagram of cities and traffic in the Yangtze River Delta (No. 42 of Paper I in 2016), and the frequency chart of American tornadoes (No. 37 in 2018). The questions focus less on global issues.

Second, the questions are characterized by small areas and a large problem. Statistically SD questions for small-scale areas account for over 50\%. Taking the small-scale area as the background, the questions pay attention to the interaction among various geographical elements and explore a certain geographical phenomenon and the gradual SD measures taken. For example, No. 37 of Paper \# in 2012 presents a contour map to examine the factors of climate, agricultural locational conditions, and sustainability of agriculture on the west coast of Peru. 
Finally, geography 3 is directly and clearly stated in SD development. Corresponding to the test syllabus, to a certain extent, the exam questions reflect the contents of desertification, rocky desertification control, forest development and protection, comprehensive development of watershed, regional agriculture development, regional industrialization and urbanization, cross-regional allocation of resources, and industrial transfer.

\subsubsection{The Difficulties of SD Questions Are Moderate}

The answer data of students in NCEE are mainly confidential and inaccessible. According to the public data [42-46] of the Education Examinations Authority of Guangdong Province (Paper I) from 2016 to 2020, the authors calculated and concluded that the average difficulty of SD exam questions is moderate (0.48) and slightly higher than that of geography (0.49). The difficulty tended to decrease since 2020 (Figure 8).

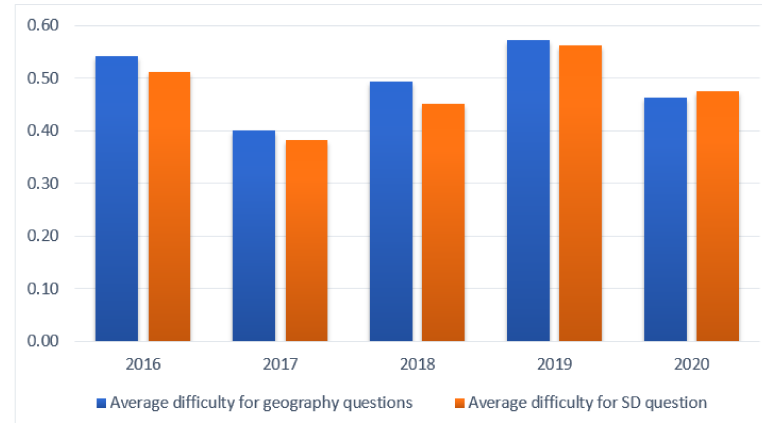

Figure 8. Comparison of average difficulty between geography and SD questions in Guangdong Province from 2016 to 2020.

The difficulty of essay questions is greater than that of multiple-choice questions. As shown in Figure 9, the difficulty of choice questions (from No. 1 to 11) is distributed uniformly. The number of difficult, medium, and easy questions is almost equal. While the difficulty of essay questions (from No. 36 to 44 ) focus on the upper-middle level. Students of different levels can be involved and has a good degree of discrimination. Statistics show that the average discrimination of SD questions is 0.34 and within good range. Moreover, open-ended questions are the most difficult. For example, No. 37(4) is an open-ended question (Table 2, the difficulty of No.37 in paper I of 2018 is 0.26 (Figure 9).

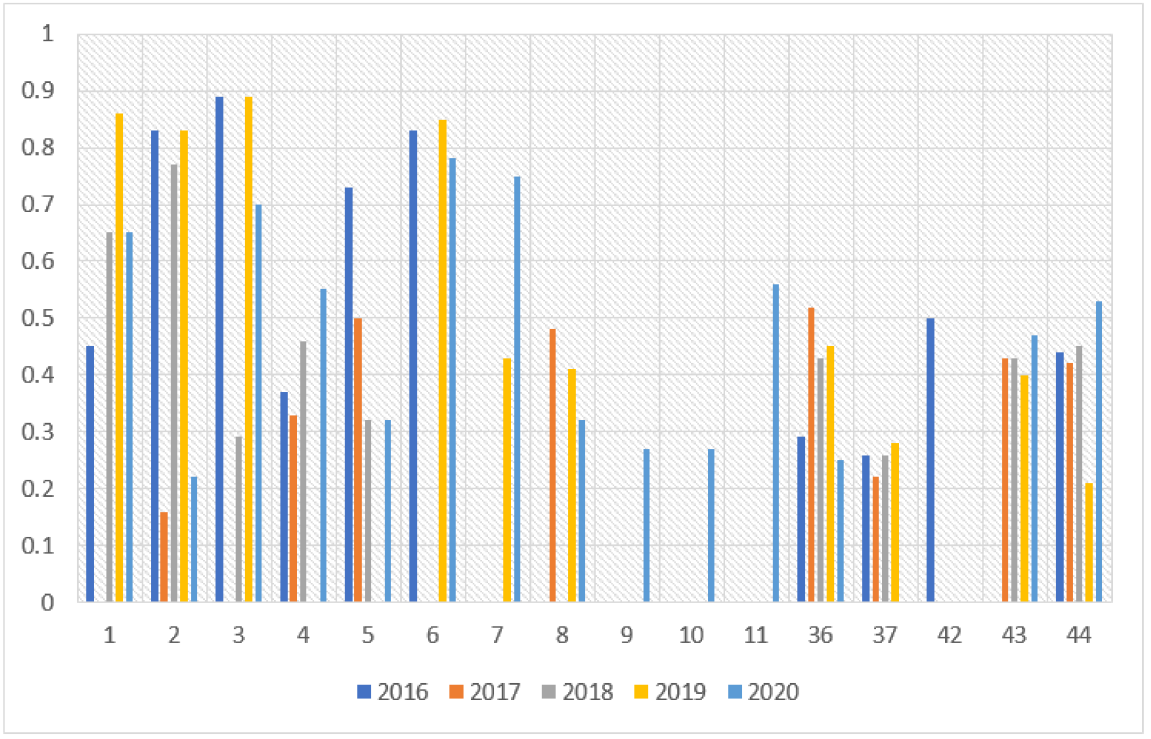

Figure 9. Statistics on the difficulty of SD question in geography paper of Guangdong Province from 2016 to 2020. 
Table 2. Examples of open-ended questions in recent five years.

\begin{tabular}{|c|c|}
\hline Papers and Years & Questions \\
\hline No. 37, Paper III, 2020 & $\begin{array}{l}\text { (4) In recent years, the green area of the Maowusu Desert has } \\
\text { gradually increased, and several people think that "the Maowusu } \\
\text { Desert will disappear soon." Do you agree? Please state your } \\
\text { opinion and provide reasons. (4 point) }\end{array}$ \\
\hline No. 37, Paper II, 2019 & $\begin{array}{l}\text { (4) Several people suggest that ski resorts in Zhejiang should } \\
\text { change from providing one-day to multi-day holiday experiences, } \\
\text { and that more hotels should be built along with intermediate and } \\
\text { advanced ski trails. Do you agree with this suggestion? Please } \\
\text { state your opinion and provide reasons. (6 point) }\end{array}$ \\
\hline No. 37, Paper I, 2018 & $\begin{array}{c}\text { (4) The outflow of Wuyur River is suggested to be restored using } \\
\text { engineering measures. Do you agree? Please provide reasons. } \\
\text { (4 point) }\end{array}$ \\
\hline No. 36, Paper II, 2018 & $\begin{array}{l}\text { (4) Several data centers on the eastern coastal region have started } \\
\text { to adopt energy saving and consumption reduction measures. Do } \\
\text { you think this is currently necessary for the data center in Gui'an } \\
\text { New Area? Please state your opinion and explain why. (4 point) }\end{array}$ \\
\hline No. 36, Paper III, 2018 & $\begin{array}{c}\text { (3) In recent years, soda ash plants have been operating at a } \\
\text { constant loss. There are different local views on whether to close } \\
\text { the soda ash plants. Please indicate the view you support and } \\
\text { provide reasons. (6 point) }\end{array}$ \\
\hline No. 36, Paper II, 2017 & $\begin{array}{c}\text { (4) Do you agree with the expansion of greenhouse agricultural } \\
\text { production in Site A? Please state your opinion and provide } \\
\text { reasons. ( } 6 \text { point) }\end{array}$ \\
\hline No. 36, Paper III, 2016 & $\begin{array}{l}\text { (3) Do you agree that tourism should be expanded in the area? } \\
\text { Please state your opinion and provide reasons. ( } 6 \text { point) }\end{array}$ \\
\hline
\end{tabular}

\section{Conclusions and Discussion}

First, the results show that $\mathrm{SD}$ is a core topic of the high school geography curriculum in China, geography is a suitable subject for SD. Most of the questions best reflect targets 6.6, water-related ecosystems. On the level of goals, most of the questions are not related to water but to zero hunger. In addition, the SDs of agriculture, tourism, transportation, settlements, regional desertification, and land degradation are also reflected well in the geography questions. However, there are some targets not presented in those topics, such as target 6.1 "equitable access to drinking water", target 11.7 "built-up area of cities".

However, Goals 5 "gender equality" and Goal 16 "Peace, justice and strong institutions" are not reflected. Goal 13 "climate change" and its effects have received little attention, possibly due to its interdisciplinary nature and high difficulty. Few SD issues also relate to Goal 14, Marine Geography, due to curriculum provision. Given difficulty of optional modules, large requirements in teaching equipment, and the lack of qualified teachers, only Environmental Protection, Natural Disasters and Prevention, and Tourism Geography are offered as optional modules in nearly all provinces [47].

Second, SD question characteristics comprise of setting open questions, using a map as a vehicle, paying attention to a situation, being scientific in origin, being close to real life, being moderately difficult, paying attention to small areas and the relationship between human and nature, and diversifying question-setting patterns. Although, the curriculum and the exams are in line with each other, as an important talent selection method, NCEE has higher requirements in powerful knowledge and higher order thinking than the curriculum. NCEE usually chooses questions to assess the ability of student to apply what they have learned to new settings and to transfer prior knowledge to new situations [48]. For types of question, open-ended questions are suitable for evaluating students' SD ability and are evidently more difficult than other question types. Although they are difficult to apply in standardized examinations because of the challenges in marking papers, it is important to teach and assess SD. It is not only about gaining knowledge (factual, conceptual, systematic) but also about participating in societal debates and reflection. As Michael Yong said, 
content with powerful knowledge enables young people to follow and participate in publics debates $[49,50]$.

Meanwhile, these issues need geographical thinking, a new way of thinking about the world with place, space and environment, understanding and explaining phenomena or events, particularly those that are beyond their personal experience [50]. Those also can relate to the characteristics of diversifying question-setting patterns. For example, if students can think about their relationships with the environment from source, sink, service and spiritual functions of the environment for people, it might even change their own behavior [51].

Third, powerful geographical knowledge requires propensity to think through alternative social, economic, and environmental futures in specific places and locational contexts [52]. Therefore, we suggest that SD question might continue to focus on regional $\mathrm{SD}$ with different scales. The study shows that $\mathrm{SD}$ goals and targets is reflected unevenly in exam questions. Under the new round of curriculum reform in China [53], it may be suggested that the less valued goals and targets should get more attention, such as marine and coastal ecosystems and sustainable natural resources. The popular targets such as tourism may be less valued. Beside the SD issues in the national region, foreign or international SD issues should get more attention, since powerful knowledge is beyond their own experience to teach students about unfamiliar places and understanding their characteristics [50]. For example, international cooperation, support for developing countries, carbon emission reduction, and climate change. Although there is growing interest in climate change, the exam still lacks of involvement with issues of climate change [54]. Furthermore, the setting of exam questions should avoid thinking about solidification and answer models, and instead inspire students to think, analyze, and solve SD problems by using powerful geographical knowledge and higher-order thinking. It is suggested that the exam needs more open-ended questions related to powerful geographical knowledge.

Author Contributions: Conceptualization, F.G. and Q.G.; methodology, F.G.; software, S.H.; validation, F.G., Y.D. and S.H.; formal analysis, F.G.; investigation, Z.Y.; resources, S.H.; data curation, Q.G.; writing-original draft preparation, F.G.; writing—review and editing, F.G.; supervision, Y.D.; project administration, Q.G.; funding acquisition, F.G. All authors have read and agreed to the published version of the manuscript.

Funding: This research was funded by National Office for Education Sciences Planning, grant number is DHA210340.

Institutional Review Board Statement: Not applicable.

Informed Consent Statement: Not applicable.

Acknowledgments: We acknowledge the help of Michael E. Meadows at the University of Cape Town, and Yu Lizhong at East China Normal University. We thank Ruiyan Hua for helping with mapping.

Conflicts of Interest: The authors declare no conflict of interest.

\section{Appendix A}

Table A1. Analytical framework.

\begin{tabular}{cc}
\hline Goal & Indicators \\
\hline $\begin{array}{c}\text { Goal 1. End poverty in all its } \\
\text { forms everywhere }\end{array}$ & $\begin{array}{c}\text { 1.5 By 2030, build the resilience of the poor and those in } \\
\text { vulnerable situations and reduce their exposure and vulnerability } \\
\text { to climate-related extreme events and other economic, social and } \\
\text { environmental shocks and disasters }\end{array}$ \\
\hline
\end{tabular}


Table A1. Cont.

\begin{tabular}{c} 
Goal \\
\hline 1.a Ensure significant mobilization of resources from a variety of \\
sources, including through enhanced development cooperation, \\
in order to provide adequate and predictable means for \\
developing countries, in particular least developed countries, to \\
implement programmes and policies to end poverty in all \\
its dimensions
\end{tabular}

2.1 By 2030, end hunger and ensure access by all people, in particular the poor and people in vulnerable situations, including infants, to safe, nutritious and sufficient food all year round

2.3 By 2030, double the agricultural productivity and incomes of small-scale food producers, in particular women, indigenous peoples, family farmers, pastoralists and fishers, including through secure and equal access to land, other productive resources and inputs, knowledge, financial services, markets and opportunities for value addition and non-farm employment

2.4 By 2030, ensure sustainable food production systems and implement resilient agricultural practices that increase productivity and production, that help maintain ecosystems, that strengthen capacity for adaptation to climate change, extreme weather, drought, flooding and other disasters and that progressively improve land and soil quality

Goal 2. End hunger, achieve food security and improved nutrition and promote sustainable agriculture
2.5 By 2020, maintain the genetic diversity of seeds, cultivated plants and farmed and domesticated animals and their related wild species, including through soundly managed and diversified seed and plant banks at the national, regional and international levels, and promote access to and fair and equitable sharing of benefits arising from the utilization of genetic resources and associated traditional knowledge, as internationally agreed

2.a Increase investment, including through enhanced international cooperation, in rural infrastructure, agricultural research and extension services, technology development and plant and livestock gene banks in order to enhance agricultural productive capacity in developing countries, in particular least developed countries

2.b Correct and prevent trade restrictions and distortions in world agricultural markets, including through the parallel elimination of all forms of agricultural export subsidies and all export measures with equivalent effect, in accordance with the mandate of the Doha Development Round

Goal 3. Ensure healthy lives and promote well-being for all at all ages
3.2 By 2030, end preventable deaths of newborns and children under 5 years of age, with all countries aiming to reduce neonatal mortality to at least as low as 12 per 1000 live births and under-5 mortality to at least as low as 25 per 1000 live births

3.7 By 2030, ensure universal access to sexual and reproductive health-care services, including for family planning, information and education, and the integration of reproductive health into national strategies and programmes 
Table A1. Cont.

\begin{tabular}{c} 
Goal Indicators \\
\hline 3.b Support the research and development of vaccines and \\
medicines for the communicable and non-communicable diseases \\
that primarily affect developing countries, provide access to \\
affordable essential medicines and vaccines, in accordance with \\
the Doha Declaration on the TRIPS Agreement and Public Health, \\
which affirms the right of developing countries to use to the full \\
the provisions in the Agreement on Trade-Related Aspects of \\
Intellectual Property Rights regarding flexibilities to protect \\
public health, and, in particular, provide access to medicines \\
for all
\end{tabular}

Goal 4. Ensure inclusive and equitable quality education and promote lifelong learning opportunities for all
4.7 By 2030, ensure that all learners acquire the knowledge and skills needed to promote sustainable development, including, among others, through education for sustainable development

and sustainable lifestyles, human rights, gender equality, promotion of a culture of peace and non-violence,

global citizenship and appreciation of cultural diversity and of culture's contribution to sustainable development

Goal 5. Achieve gender equality and empower all women and girls
5.1 End all forms of discrimination against all women and girls everywhere

6.1 By 2030, achieve universal and equitable access to safe and affordable drinking water for all

6.3 By 2030, improve water quality by reducing pollution, eliminating dumping and minimizing release of hazardous chemicals and materials, halving the proportion of untreated wastewater and substantially increasing recycling and safe reuse globally

Goal 6. Ensure availability and sustainable management of water and sanitation for all
6.5 By 2030, implement integrated water resources management at all levels, including through transboundary cooperation as appropriate

6.6 By 2020, protect and restore water-related ecosystems, including mountains, forests, wetlands, rivers, aquifers and lakes

6.a By 2030, expand international cooperation and capacity-building support to developing countries in water- and sanitation-related activities and programmes, including water harvesting, desalination, water efficiency, wastewater treatment, recycling and reuse technologies

7.1 By 2030, ensure universal access to affordable, reliable and modern energy services

Goal 7. Ensure access to affordable, reliable, sustainable and modern energy for all

\subsection{By 2030, increase substantially the share of renewable energy in the global energy mix}

7.a By 2030, enhance international cooperation to facilitate access to clean energy research and technology, including renewable energy, energy efficiency and advanced and cleaner fossil-fuel technology, and promote investment in energy infrastructure and clean energy technology 
Table A1. Cont.

\begin{tabular}{|c|c|}
\hline Goal & Indicators \\
\hline \multirow{5}{*}{$\begin{array}{l}\text { Goal 8. Promote sustained, } \\
\text { inclusive and sustainable } \\
\text { economic growth, full and } \\
\text { productive employment and } \\
\text { decent work for all }\end{array}$} & $\begin{array}{c}\text { 8.1 Sustain per capita economic growth in accordance with } \\
\text { national circumstances and, in particular, at least } 7 \text { per cent gross } \\
\text { domestic product growth per annum in the least developed } \\
\text { countries }\end{array}$ \\
\hline & $\begin{array}{c}\text { 8.2 Achieve higher levels of economic productivity through } \\
\text { diversification, technological upgrading and innovation, } \\
\text { including through a focus on high-value added and } \\
\text { labour-intensive sectors }\end{array}$ \\
\hline & $\begin{array}{l}\text { 8.3 Promote development-oriented policies that support } \\
\text { productive activities, decent job creation, entrepreneurship, } \\
\text { creativity and innovation, and encourage the formalization } \\
\text { and growth of micro-, small- and medium-sized enterprises, } \\
\text { including through access to financial services }\end{array}$ \\
\hline & $\begin{array}{l}8.9 \text { By 2030, devise and implement policies to promote sustainable } \\
\text { tourism that creates jobs and promotes local culture and products }\end{array}$ \\
\hline & $\begin{array}{l}\text { 8.a Increase Aid for Trade support for developing countries, in } \\
\text { particular least developed countries, including through the } \\
\text { Enhanced Integrated Framework for Trade- related Technical } \\
\text { Assistance to Least Developed Countries }\end{array}$ \\
\hline \multirow{5}{*}{$\begin{array}{l}\text { Goal 9. Build resilient } \\
\text { infrastructure, promote } \\
\text { inclusive and sustainable } \\
\text { industrialization and foster } \\
\text { innovation }\end{array}$} & $\begin{array}{l}9.1 \text { Develop quality, reliable, sustainable and resilient } \\
\text { infrastructure, including regional and transborder infrastructure, } \\
\text { to support economic development and human well-being, with a } \\
\text { focus on affordable and equitable access for all }\end{array}$ \\
\hline & $\begin{array}{l}\text { 9.2 Promote inclusive and sustainable industrialization and, by } \\
\text { 2030, significantly raise industry's share of employment and gross } \\
\text { domestic product, in line with national circumstances, and double } \\
\text { its share in least developed countries }\end{array}$ \\
\hline & $\begin{array}{l}\text { 9.4 By 2030, upgrade infrastructure and retrofit industries to make } \\
\text { them sustainable, with increased resource-use efficiency and } \\
\text { greater adoption of clean and environmentally sound } \\
\text { technologies and industrial processes, with all countries taking } \\
\text { action in accordance with their respective capabilities }\end{array}$ \\
\hline & $\begin{array}{c}\text { 9.a Facilitate sustainable and resilient infrastructure development } \\
\text { in developing countries through enhanced financial, technological } \\
\text { and technical support to African countries, least developed } \\
\text { countries, landlocked developing countries and small island } \\
\text { developing States }\end{array}$ \\
\hline & $\begin{array}{l}\text { 9.c Significantly increase access to information and } \\
\text { communications technology and strive to provide universal and } \\
\text { affordable access to the Internet in least developed countries } \\
\text { by } 2020\end{array}$ \\
\hline \multirow{2}{*}{$\begin{array}{l}\text { Goal 10. Reduce inequality } \\
\text { within and among countries }\end{array}$} & $\begin{array}{l}10.1 \text { By } 2030 \text {, progressively achieve and sustain income growth of } \\
\text { the bottom } 40 \text { per cent of the population at a rate higher than the } \\
\text { national average }\end{array}$ \\
\hline & $\begin{array}{l}\text { 10.7 Facilitate orderly, safe, regular and responsible migration and } \\
\text { mobility of people, including through the implementation of } \\
\text { planned and well-managed migration policies }\end{array}$ \\
\hline
\end{tabular}


Table A1. Cont.

\begin{tabular}{|c|c|}
\hline Goal & Indicators \\
\hline & $\begin{array}{l}11.2 \text { By } 2030, \text { provide access to safe, affordable, accessible and } \\
\text { sustainable transport systems for all, improving road safety, } \\
\text { notably by expanding public transport, with special attention to } \\
\text { the needs of those in vulnerable situations, women, children, } \\
\text { persons with disabilities and older persons }\end{array}$ \\
\hline
\end{tabular}

11.3 By 2030, enhance inclusive and sustainable urbanization and capacity for participatory, integrated and sustainable human settlement planning and management in all countries

11.4 Strengthen efforts to protect and safeguard the world's cultural and natural heritage

11.5 By 2030, significantly reduce the number of deaths and the number of people affected and substantially decrease the direct economic losses relative to global gross domestic product caused

Goal 11. Make cities and human settlements inclusive, sustainable safe, resilient and

by disasters, including water-related disasters, with a focus on protecting the poor and people in vulnerable situations

11.6 By 2030, reduce the adverse per capita environmental impact of cities, including by paying special attention to air quality and municipal and other waste management

11.7 By 2030, provide universal access to safe, inclusive and accessible, green and public spaces, in particular for women and children, older persons and persons with disabilities

11.a Support positive economic, social and environmental links between urban, peri-urban and rural areas by strengthening national and regional development planning

11.b By 2020, substantially increase the number of cities and human settlements adopting and implementing integrated policies and plans towards inclusion, resource efficiency, mitigation and adaptation to climate change, resilience to disasters, and develop and implement, in line with the Sendai

Framework for Disaster Risk Reduction 2015-2030, holistic disaster risk management at all levels

11.c Support least developed countries, including through financial and technical assistance, in building sustainable and resilient buildings utilizing local materials

12.2 By 2030, achieve the sustainable management and efficient use of natural resources

12.3 By 2030, halve per capita global food waste at the retail and consumer levels and reduce food losses along production and supply chains, including post-harvest losses

Goal 12. Ensure sustainable consumption and production patterns
12.4 By 2020, achieve the environmentally sound management of chemicals and all wastes throughout their life cycle, in accordance with agreed international frameworks, and significantly reduce

their release to air, water and soil in order to minimize their adverse impacts on human health and the environment

12.5 By 2030, substantially reduce waste generation through prevention, reduction, recycling and reuse 
Table A1. Cont.

\begin{tabular}{|c|c|}
\hline Goal & Indicators \\
\hline & $\begin{array}{l}\text { 12.6 Encourage companies, especially large and transnational } \\
\text { companies, to adopt sustainable practices and to integrate } \\
\text { sustainability information into their reporting cycle }\end{array}$ \\
\hline & $\begin{array}{c}12.8 \text { By } 2030, \text { ensure that people everywhere have the relevant } \\
\text { information and awareness for sustainable development and } \\
\text { lifestyles in harmony with nature }\end{array}$ \\
\hline & $\begin{array}{l}\text { 12.a Support developing countries to strengthen their scientific } \\
\text { and technological capacity to move towards more sustainable } \\
\text { patterns of consumption and production }\end{array}$ \\
\hline & $\begin{array}{c}\text { 12.b Develop and implement tools to monitor sustainable } \\
\text { development impacts for sustainable tourism that creates jobs } \\
\text { and promotes local culture and products }\end{array}$ \\
\hline & $\begin{array}{l}\text { 12.c Rationalize inefficient fossil-fuel subsidies that encourage } \\
\text { wasteful consumption by removing market distortions, in } \\
\text { accordance with national circumstances, including by } \\
\text { restructuring taxation and phasing out those harmful subsidies, } \\
\text { where they exist, to reflect their environmental impacts, taking } \\
\text { fully into account the specific needs and conditions of developing } \\
\text { countries and minimizing the possible adverse impacts on their } \\
\text { development in a manner that protects the poor and the } \\
\text { affected communities }\end{array}$ \\
\hline
\end{tabular}

13.1 Strengthen resilience and adaptive capacity to climaterelated hazards and natural disasters in all countries

Goal 13. Take urgent action to combat climate change and its impacts 3

13.2 Integrate climate change measures into national policies, strategies and planning

13.3 Improve education, awareness-raising and human and institutional capacity on climate change mitigation, adaptation, impact reduction and early warning

14.1 By 2025, prevent and significantly reduce marine pollution of all kinds, in particular from land-based activities, including marine debris and nutrient pollution

14.2 By 2020, sustainably manage and protect marine and coastal ecosystems to avoid significant adverse impacts, including by strengthening their resilience, and take action for their restoration in order to achieve healthy and productive oceans

14.3 Minimize and address the impacts of ocean acidification, including through enhanced scientific cooperation at all levels

Goal 14. Conserve and sustainably use the oceans, seas and marine resources for sustainable development
14.4 By 2020, effectively regulate harvesting and end overfishing, illegal, unreported and unregulated fishing and destructive fishing practices and implement science-based management plans, in order to restore fish stocks in the shortest time feasible, at least to levels that can produce maximum sustainable yield as determined by their biological characteristics

14.a Increase scientific knowledge, develop research capacity and transfer marine technology, taking into account the

Intergovernmental Oceanographic Commission Criteria and Guidelines on the Transfer of Marine Technology, in order to improve ocean health and to enhance the contribution of marine biodiversity to the development of developing countries, in particular small island developing States and least developed countries 
Table A1. Cont.

\begin{tabular}{|c|c|}
\hline Goal & Indicators \\
\hline \multirow{8}{*}{$\begin{array}{l}\text { Goal } 15 \text {. Protect, restore and } \\
\text { promote sustainable use of } \\
\text { terrestrial ecosystems, } \\
\text { sustainably manage forests, } \\
\text { combat desertification, and } \\
\text { halt and reverse land } \\
\text { degradation and halt } \\
\text { biodiversity loss }\end{array}$} & $\begin{array}{c}\text { 15.1 By 2020, ensure the conservation, restoration and sustainable } \\
\text { use of terrestrial and inland freshwater } \\
\text { ecosystems and their services, in particular forests, wetlands, } \\
\text { mountains and drylands, in line with obligations under } \\
\text { international agreements }\end{array}$ \\
\hline & $\begin{array}{l}\text { 15.2 By } 2020, \text { promote the implementation of sustainable } \\
\text { management of all types of forests, halt deforestation, } \\
\text { restore degraded forests and substantially increase } \\
\text { afforestation and reforestation globally }\end{array}$ \\
\hline & $\begin{array}{c}\text { 15.3 By 2030, combat desertification, restore degraded land and } \\
\text { soil, including land affected by desertification, } \\
\text { drought and floods, and strive to achieve a land degradation- } \\
\text { neutral world }\end{array}$ \\
\hline & $\begin{array}{l}15.4 \text { By } 2030 \text {, ensure the conservation of mountain ecosystems, } \\
\text { including their biodiversity, in order to enhance their capacity to } \\
\text { provide benefits that are essential for } \\
\text { sustainable development }\end{array}$ \\
\hline & $\begin{array}{l}15.5 \text { Take urgent and significant action to reduce the } \\
\text { degradation of natural habitats, halt the loss of biodiversity and, } \\
\text { by 2020, protect and prevent the extinction of } \\
\text { threatened species }\end{array}$ \\
\hline & $\begin{array}{l}\text { 15.7 Take urgent action to end poaching and trafficking of } \\
\text { protected species of flora and fauna and address both } \\
\text { demand and supply of illegal wildlife products }\end{array}$ \\
\hline & $\begin{array}{l}15.8 \text { By } 2020 \text {, introduce measures to prevent the } \\
\text { introduction and significantly reduce the impact of invasive alien } \\
\text { species on land and water ecosystems and control or } \\
\text { eradicate the priority species }\end{array}$ \\
\hline & $\begin{array}{c}15.9 \text { By 2020, integrate ecosystem and biodiversity values into } \\
\text { national and local planning, development processes, poverty } \\
\text { reduction strategies and accounts }\end{array}$ \\
\hline
\end{tabular}

Goal 16. Promote peaceful and inclusive societies for sustainable development, provide access to justice for all and build effective, accountable and inclusive institutions at all levels

Goal 17. Strengthen the means of implementation and revitalize the Global Partnership for Sustainable Development 16.b Promote and enforce non-discriminatory laws and policies for sustainable development

17.6 Enhance North-South, South-South and triangular regional and international cooperation on and access to science, technology and innovation and enhance knowledge- sharing on mutually agreed terms, including through improved coordination among existing mechanisms, in particular at the United Nations level, and through a global technology facilitation mechanism

17.9 Enhance international support for implementing effective and targeted capacity-building in developing countries to support national plans to implement all the Sustainable Development

Goals, including through North- South, South-South and triangular cooperation

17.10 Promote a universal, rules-based, open, non-discriminatory and equitable multilateral trading system under the World Trade

Organization, including through the conclusion of negotiations under its Doha Development Agenda 


\section{References}

1. UN. Transforming Our World: The 2030 Agenda for Sustainable Development; United Nations: New York, NY, USA, 2015.

2. UN. Global Indicator Framework for the Sustainable Development Goals and Targets of the 2030 Agenda for Sustainable Development. Available online: https://unstats.un.org/sdgs/indicators/indicators-list (accessed on 1 September 2021).

3. Yuan, M. Geographical information science for the United Nations' 2030 agenda for sustainable development. Int. J. Geogr. Inf. Sci. 2020, 35, 1-8. [CrossRef]

4. Reinfried, S.; Rempfler, A. Lucerne declaration on geographical education for sustainable development. Geogr. Forsch. 2007, 42, 243-250.

5. $\quad$ Guo, F.; Lane, J.; Duan, Y.; Stoltman, J.P.; Khlebosolova, O.; Lei, H.; Zhou, W. Sustainable Development in Geography Education for Middle School in China. Sustainability 2018, 10, 3896. [CrossRef]

6. Nevin, E. Education and sustainable development. Policy Pract. Dev. Educ. Rev. 2008, 6, 49-62.

7. Shulla, K.; Filho, W.L.; Lardjane, S.; Sommer, J.H.; Borgemeister, C. Sustainable development education in the context of the 2030 Agenda for sustainable development. Int. J. Sustain. Dev. World Ecol. 2020, 27, 458-468. [CrossRef]

8. Zguir, M.F.; Dubis, S.; Koç, M. Embedding Education for Sustainable Development (ESD) and SDGs values in curriculum: A comparative review on Qatar, Singapore and New Zealand. J. Clean. Prod. 2021, 319, 128534. [CrossRef]

9. Littledyke, M. Science education for environmental awareness: Approaches to integrating cognitive and affective domains. Environ. Educ. Res. 2008, 14,1-17. [CrossRef]

10. Liu, L.; Chen, C. Developing New Curriculum of Geography in High School with Sustainable Development. China Education Newspaper, 16 December 2005; p. 5.

11. Jackson, P. Thinking Geographically. Geography 2006, 91, 199-204. [CrossRef]

12. Qiu, J. The role of geography in sustainable development. Natl. Sci. Rev. 2016, 4, 140-143. [CrossRef]

13. Uitto, A.; Saloranta, S. Subject Teachers as Educators for Sustainability: A Survey Study. Educ. Sci. 2017, 7, 8. [CrossRef]

14. Rauch, F.; Steiner, R. Competences for Education for Sustainable Development in Teacher Education. Cent. Educ. Policy Stud. J. 2013, 3, 9-24. [CrossRef]

15. Filho, W.L.; Levesque, V.R.; Salvia, A.L.; Paço, A.; Fritzen, B.; Frankenberger, F.; Damke, L.I.; Brandli, L.L.; Ávila, L.V.; Mifsud, M.; et al. University teaching staff and sustainable development: An assessment of competences. Sustain. Sci. 2020, 16, 101-116. [CrossRef]

16. Cifuentes-Faura, J.; Faura-Martínez, U.; Lafuente-Lechuga, M. Assessment of Sustainable Development in Secondary School Economics Students According to Gender. Sustainability 2020, 12, 5353. [CrossRef]

17. Rychen, D. Key competencies for the knowledge society: A contribution from the OECD project definition and selection of competencies (deseco). In Proceedings of the Education-Lifelong Learning and the Knowledge Economy Conference, Stuttgart, Germany, 9-10 October 2002.

18. UNESCO. Education for Sustainable Development Sourcebook; Langer, H., Ed.; Place de Fontenoy: Paris, France, 2012.

19. Lu, A. Interpretation of geography exam questions of Paper 1 in 2016. Geogr. Teach. 2016, 13, 56-58.

20. Liu, X. Analysis of New Standard Comprehensive Matriculation National Geographic Test Papers in 2010-2016. Master's Thesis, Ludong University, Yantai, China, 2017.

21. Wang, M. Technology of answering questions about human-land relationship. Test Quest. Study. 2016, 1, 26-31.

22. Zhou, Y. Analyze the answers of question in college entrance examination and explore the thinking mode of answering questionstaking the sustainable development of agricultural products as an example. Teach. Exam. 2018, 9, 33-34.

23. Zhang, W. Question design of regional sustainable development. Geogr. Teach. 2019, 9, 48-49.

24. Qiu, J.; Hung, D.; Zhang, Z. "Lucid waters and lush mountains are invaluable assets" test item design-natural environment protection and agricultural sustainable development in karst areas. Trop. Geomorphol. 2019, 40, 82-84.

25. MOE\&PRC. Notice of the Ministry of Education Issued the Curriculum Plan of Ordinary Senior high School and the Curriculum Standards (Experimental Version) of Fifteen Subjects such as Chinese. Available online: http://www.moe.gov.cn/srcsite/A26/s8 001/200303/t20030331_167349.html (accessed on 1 September 2021).

26. MOE\&PRC. High School Geography Curriculum Standard (Experimental Version); People's Education Press: Beijing, China, 2003.

27. Duan, Y.; Chen, C. Opinion on the revision of high school geography standard. Basic Educ. Curric. 2013, 5, 12-14.

28. Chen, C. The Core Topic of Geography Curriculum in High School. Geogr. Teach. 1996, 5, 12-14.

29. Chen, C.; Fan, J. The Interpretation of High School Geography Curriculum Standard (Experimental Version); Jiangsu Education Publishing House: Nanjing, China, 2006; p. 323.

30. Liu, l. Review and Reflection of provincial question-setting reform of College Entrance Examination. Educ. Exam. 2020, 1, 12-16.

31. MOE\&PRC. National Medium and Long-term Education Reform and Development Plan (2010-2020). MOE\&PRC, Ed.; 2010. Available online: http://www.moe.gov.cn/srcsite/A01/s7048/201007/t20100729_171904.html (accessed on 4 September 2021).

32. Council, S. The Implementation Opinions of the State Council on Deepening the Reform of Examination and Enrollment System. 2014. Available online: http:/ /english.www.gov.cn/archive/state_council_gazette/2015/06/05/content_281475121375602.htm (accessed on 7 September 2021).

33. Yuan, G. Strive to overcome eight difficult problems of education reform and development-an interview with the minister of education. Xinhua News Agency, 2 February 2014. 
34. MOE\&PRC. Notice of the Ministry of Education on the Interim Measures for the Administration of the Provincial Question-setting of the National Unified College Entrance Examination; MOE\&PRC: Beijing, China, 2006. Available online: http://www.moe.gov.cn/jyb_ xxgk/gk_gbgg/moe_0/moe_1133/moe_1304/tnull_18439.html (accessed on 7 September 2021).

35. Liu, B. Retrospect and enlightenment of the provincial question-setting reform of college entrance examination. Jiangsu High. Education. 2017, 2, 76-79.

36. MOE\&PRC. Notice of the Ministry of Education on Printing and Distributing the Syllabus of Seven Subjects Including Chinese for Full-Time Senior Middle School; MOE\&PRC: Beijing, China, 2002. Available online: http://www.moe.gov.cn/jyb_xxgk/gk_gbgg/ moe_0/moe_8/moe_25/tnull_237.html (accessed on 4 September 2021).

37. NEEA. 2019 Geography Test Syllabus for National Unified College Entrance Examination. Available online: http:/ / gaokao.neea. edu.cn/html1/report/19012/5851-1.htm (accessed on 1 May 2021).

38. China Tourism Academy. Annual Report of China Domestic Tourism Development 2021; China Tourism Academy: Beijing, China, 2021.

39. Jean, P.B.; Cai, Z. French Rhone river and its basin hrnessing. World Reg. Stud. 2015, 24, 8.

40. Jin, X.; Deng, H.; Hu, D. Habitat changing of the giant panda in qinling mountain over 30 years from 1976 to 2007. Chin. J. Zool. 2012, 47,6 .

41. Gong, S. Framework of human geography research. In Proceedings of the 2003 Academic Annual Meeting of Chinese Geographical Society, Wuhan, China, 11-14 July 2003; p. 154.

42. EEAGP. Annual Report of Guangdong College Entrance Examination 2016; Guangdong Higher Education Press: Guangdong, China, 2016; pp. 82-85.

43. EEAGP. Annual Report of Guangdong College Entrance Examination 2018; Guangdong Higher Education Press: Guangzhou, China, 2018; pp. 85-88.

44. EEAGP. Annual Report of Guangdong College Entrance Examination 2019; Guangdong Higher Education Press: Guangzhou, China, 2019; pp. 77-79.

45. EEAGP. Annual Report of Guangdong College Entrance Examination 2020; Guangdong Higher Education Press: Guangzhou, China, 2020; pp. 73-75.

46. EEAGP. Annual Report of Guangdong College Entrance Examination 2021; Guangdong Higher Education Press: Guangzhou, China, 2021; pp. 73-75.

47. Guo, F. The Implementation and Test Evaluation of the Senior Geography Optional Modules in New Curriculum Reform. Master's Thesis, East China Normal University, Shanghai, China, 2011.

48. Shiveley, J.; Misco, T. Reclaiming generalizations in social studies education. Soc. Stud. Res. Pract. 2009, 4, 73-78.

49. Young, M.; Muller, J. On the powers of powerful knowledge. Rev. Education. 2013, 1, 229-250. [CrossRef]

50. Maude, A. What might powerful geographical knowledge look like? Geography 2016, 101, 70-76. [CrossRef]

51. Maude, A. A sustainable view of sustainability? Geography 2014, 99, 47-50. [CrossRef]

52. Lambert, D.; Solem, M.; Tani, S. Achieving Human Potential Through Geography Education: A Capabilities Approach to Curriculum Making in Schools. Ann. Assoc. Am. Geogr. 2015, 105, 723-735. [CrossRef]

53. MOE\&PRC. High School Geography Curriculum Standard; People's Education Press: Beijing, China, 2020.

54. Whalley, W.B. The science tradition in physical geography: 2016 A level specifications and 'powerful geography'. Geography 2020, 105, 142-156. [CrossRef] 